\title{
Determination of ticlopidine in human plasma by capillary gas chromatography with ion trap detection
}

\author{
Angelina Pena*, Celeste Lino, M. Irene N. Silveira \\ Laboratory of Bromatology, Faculty of Pharmacy, University of Coimbra, 3000 Coimbra, Portugal
}

Received 24 April 2002; received in revised form 20 December 2002; accepted 27 December 2002

\begin{abstract}
A gas chromatographic method for determination of ticlopidine in human plasma using mass spectrometric detection was developed. A Perkin Elmer model 8500 gas chromatograph coupled to an ion trap detector (ITD) in electron impact mode (EI) was used. The gas chromatograph was fitted with a $30 \mathrm{~m} \times 0.32 \mathrm{~mm}$ i.d., DB-17 capillary column with a film thickness of $0.25 \mu \mathrm{m}$. The compounds were isolated from plasma by Extrelut-1 solid-phase extraction using hexane as the solvent of elution. The detection and quantification limits for this method were $0.005 \mathrm{and} 0.01 \mu \mathrm{g} / \mathrm{ml}$, respectively. The calibration curves were linear from 0.01 and $2.5 \mu \mathrm{g} / \mathrm{ml}$. Recoveries from human plasma spiked at 0.01 and $2.0 \mu \mathrm{g} / \mathrm{ml}$ ranged from 84.4 and $87.3 \%$. The coefficient of variation $(\mathrm{CV})$ was between 5.1 and $6.9 \%$. The results show that the sensitivity, accuracy and precision of the method are adequate for the determination of ticlopidine in human plasma samples. The ITD in SIM mode allows the unequivocal identification of ticlopidine. The suitability of this method was evaluated in the determination of ticlopidine in plasma from healthy volunteers following oral administration of a dose of $500 \mathrm{mg} /$ day.
\end{abstract}

(C) 2003 Elsevier Science B.V. All rights reserved.

Keywords: Ticlopidine; Human plasma; Gas chromatography-mass spectrometric detection

\section{Introduction}

Ticlopidine (Fig. 1), is a potent and long acting inhibitor of platelet aggregation [1]. Platelets contribute significantly to arterial-occlusive thrombosis, one of the major causes of death and disease throughout the world. Consequently,

\footnotetext{
* Corresponding author. Tel.: +351-239-85-9994; fax: + 351-239-82-7126.

E-mail address: apena@ci.uc.pt (A. Pena).
}

inhibiting platelet function is a potentially important therapeutic goal. Among agents that inhibit platelet function, ticlopidine shows a wide spectrum of antiplatelet activity [2]. Ticlopidine is superior to aspirin and dipyridamole as antithrombotic agent towards different kinds of experimental thrombosis $[3,4]$.

Studies in animals and man demonstrated that ticlopidine is a potent inhibitor of platelet aggregation induced by adenosine diphosphate and variably inhibits aggregation due to collagen, adrenaline (epinephrine), arachidonic acid, thrombin and platelet activating factor [5]. 


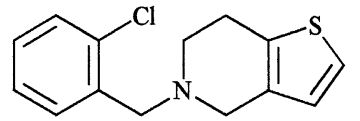

Fig. 1. Chemical structure of ticlopidine.

Usually anti-thrombotic therapy is a long-term process, and its important to monitor not only the anti-thrombotic effect but also drug concentration in plasma.

Three main analytical techniques are described for the determination of unchanged ticlopidine in plasma or urine: high-performance liquid chromatography with ultraviolet detection (HPLC-UV) [6-10], gas-liquid chromatography with nitrogen detection (GC-NPD) [11] and gas chromatography-mass spectrometry (GC-MS) [12,13].

High-performance liquid chromatographic methods have been reported for ticlopidine determination in human plasma with UV detection at 230-235 nm [6,7], and at a lower wavelength (213-215 nm), corresponding to the maximum of absorption, and consequently to achieve a better sensitivity [8-10].

Arnoux et al. [12] proceed to the comparison of the three methods reported in literature for the determination of ticlopidine in plasma: HPLCUV, GC-NPD and GC-MS. They observed that GC methods are preferable to the HPLC method evaluated. The GC-NPD method was found to be a suitable technique but, for pharmacokinetic studies, GC-MS was found to be the most reproducible, sensitive and specific assay.

In addition, effective control requires appropriate analytical methodology, which must provide enough sensitivity as well as the ability to confirm the identity of the analytes. Owing to its specificity, gas chromatography coupled with mass spectrometry detection is a powerful confirmation technique.

Therefore, in our laboratory we have developed a analytical method by gas chromatography coupled with a ion trap detector (ITD) for the determination of ticlopidine in human plasma.

For sample processing, liquid-liquid extraction procedure using $2 \%$ isoamylic alcohol in $n$-hexane [10], $n$-heptane-isoamyl alcohol mixture (98.5:1.5, v/v) [6] and $n$-hexane [7] are described in the literature. Methods based in solid-phase extraction using Extrelut [12] and Bond Elut $\mathrm{C}_{18}$ columns [8] are also reported.

In this work, blood samples were centrifuged immediately after being collected. Solid-phase extraction of ticlopidine from plasma was performed using Extrelut-1 columns, according Arnoux method [12].

Ticlopidine dichloro derivative, which we used as internal standard for quantitative determinations, has been described in a number of reports $[7-9,12]$.

The aim of this study was to develop and validate a GC-MS method for measuring ticlopidine levels in plasma samples. After validation the method was evaluated in samples collected from healthy volunteers who were administered a dose of $500 \mathrm{mg} /$ day.

The analytical method described in this paper is reproducible, sensitive and specific and allows the routine assessment of ticlopidine plasmatic concentrations.

\section{Experimental}

\subsection{Reagents and solvents}

Each batch of reagents and solvents was tested for any impurities before use. Ticlopidine-[5- $(o-$ chlorobenzyl)]-4,5,6,7-tetrahydrothieno-[3,2-c] pyridine hydrochloride and the internal standard 5-[2,4-(o-dichlorobenzyl)] 4,5,6,7,-tetrahydrothieno-[3,2-c]pyridine hydrochloride (PCR 2735) were obtained from Sanofi Recherche (Montpellier, France).

Methanol and hexane Baker analysed for environmental monitoring procedures by capillary GC were purchased from Baker (Netherlands). Extrelut-1 columns were supplied by Merck (Darmstadt, Germany).

Water was obtained by purifying distilled water in a Milli-Q filtration system (Millipore, Bedford, MA).

Individual stock standards solutions $(1 \mathrm{mg} / \mathrm{ml})$ were prepared in methanol and stored at $4{ }^{\circ} \mathrm{C}$ for a maximum period of 1 month. The final working 
standard solutions were prepared in methanol at $0.01,0.05,0.2,0.5,1.0,2.0$ and $2.5 \mu \mathrm{g} / \mathrm{ml}$.

\subsection{Apparatus and chromatographic conditions}

A Perkin Elmer model 8500 gas chromatograph coupled to an ITD (Finnigan Mat 800) in electron impact mode (EI) was used. The gas chromatograph was fitted with a $30 \mathrm{~m} \times 0.32 \mathrm{~mm}$ i.d., DB17 capillary column with a film thickness of 0.25 $\mu \mathrm{m}$ (J\&W Scientific). The helium flow used was 1 $\mathrm{ml} / \mathrm{min}$. The linear velocity of helium (carrier gas) was $32 \mathrm{~cm}^{-1}$ at $200{ }^{\circ} \mathrm{C}$ and a column head pressure of $30 \mathrm{KPa}$. Injector temperature was $280{ }^{\circ} \mathrm{C}$. Samples were injected in the splitless mode with a 1 min purge off. The oven temperature was programmed as follows: initial temperature of $50{ }^{\circ} \mathrm{C}$ and hold for $1 \mathrm{~min}$, and temperature increase at a rate of $40{ }^{\circ} \mathrm{C} / \mathrm{min}$; first intermediate temperature of $200{ }^{\circ} \mathrm{C}$ and temperature increase at a rate of $10{ }^{\circ} \mathrm{C} / \mathrm{min}$; second intermediate temperature of $252{ }^{\circ} \mathrm{C}$ and temperature increase at a rate of $40{ }^{\circ} \mathrm{C} / \mathrm{min}$; final temperature of $270{ }^{\circ} \mathrm{C}$ and hold for $1 \mathrm{~min}$. The injection volume used was $1 \mu \mathrm{l}$.

The column was directly inserted into the ITD source. The mass spectrometric conditions were as follows: electron energy, $70 \mathrm{eV}$; electron multiplier voltage, $2300 \mathrm{~V}$; transfer line temperature $270{ }^{\circ} \mathrm{C}$. The ITD was optimised with the automatic set-up program in the AUTOMATIC GAIN CONTROL software and produced mass spectrum that met calibration compound (perfluorotributylamine) performance criteria. Tune values used to set the resolution at $\mathrm{m} / z 69,131,264$ and 502 , in the spectrum of perfluorotributylamine, were 50, 95, 130 and 200 , respectively at a 'B' value of 5000 . The computer system connected to the mass spectrometer must allow continuous acquisition and storage of all mass spectra obtained, throughout the complete chromatographic program. Mass spectra were normalised after background subtraction.

\subsection{Sample preparation}

Blood samples $(3.0 \mathrm{ml})$, obtained from 10 healthy volunteers after administration of a dose of $500 \mathrm{mg} / \mathrm{day}$, were collected in heparinized glass

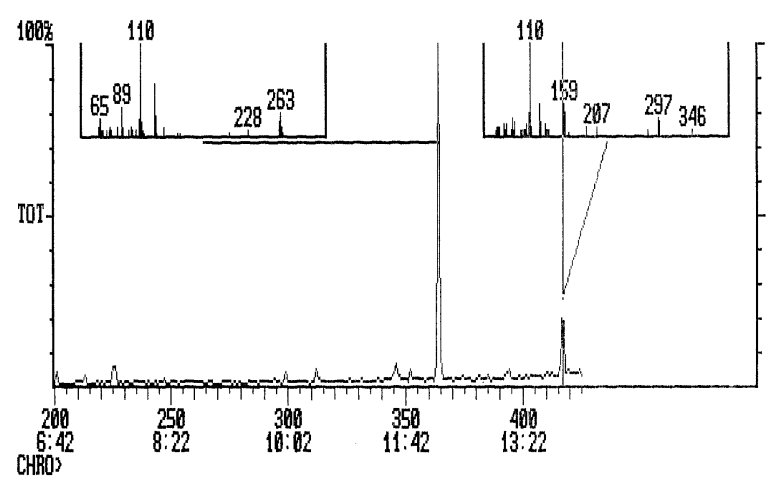

Fig. 2. Total ion chromatogram of ticlopidine and internal standard.

centrifuge tubes without anticoagulants. After immediate centrifugation, the plasma was transferred to a 10-ml glass-stoppered tube and stored at $-30{ }^{\circ} \mathrm{C}$ until the analysis.

\subsection{Extraction procedure}

The samples of plasma $(0.25 \mathrm{ml})$ were diluted with $0.25 \mathrm{ml}$ distilled water and were spiked with $0.5 \mu \mathrm{g}$ of the internal standard. After vortexing (10 s) the mixture was applied to the Extrelut-1 column. The column was left standing for $20 \mathrm{~min}$ and compounds were eluted with $6.5 \mathrm{ml}$ of hexane into a 10-ml glass tube. The eluant was evaporated under a stream of nitrogen at $30^{\circ} \mathrm{C}$ and the resulting dry residue was dissolved in $0.1 \mathrm{ml}$ of hexane.

\section{Results}

\subsection{Chromatographic analysis and detection}

The usefulness of the DB-17 column is clearly shown by the adequate resolution of the ticlopidine and the internal standard in the total ion chromatogram, produced by scanning over the mass range $m / z$ 200-500 amu (Fig. 2).

The presence of these compounds in samples was confirmed by comparison of their GC retention times and ion trap mass spectra with those of calibration standards analysed under identical 


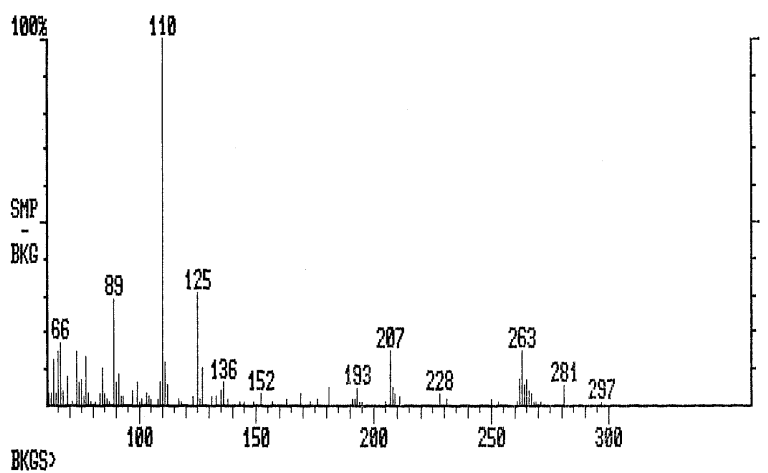

Fig. 3. Mass spectra of ticlopidine.

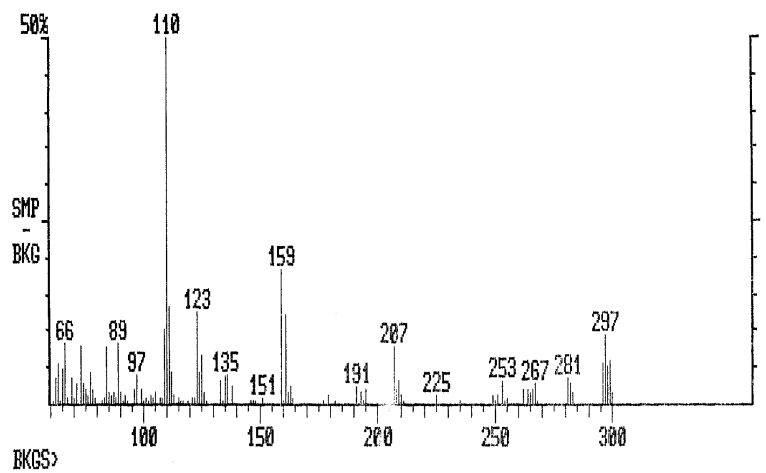

Fig. 4. Mass spectra of internal standard.

conditions and by additional library searches. Ion trap mass spectras of ticlopidine and internal standard ranged from 0 to $300 \mathrm{amu}$ are shown in Figs. 3 and 4.

The mass spectrum of ticlopidine is characterised by a molecular ion at $m / z 263\left(\mathrm{M}^{+}\right)$, and fragments at $125\left(\mathrm{M}-\mathrm{C}_{7} \mathrm{H}_{8} \mathrm{NS}\right)$ and $110(\mathrm{M}-$ $\mathrm{C}_{8} \mathrm{H}_{8} \mathrm{NCl}$ ) (Fig. 3). The mass spectrum of ticlopi- dine dichloro derivative, used as internal standard, is characterised by a molecular ion at $\mathrm{m} / \mathrm{z} 297$ $\left(\mathrm{M}^{+}\right)$, and fragments at $159\left(\mathrm{M}-\mathrm{C}_{7} \mathrm{H}_{8} \mathrm{NS}\right)$ and 110 $\left(\mathrm{M}-\mathrm{C}_{8} \mathrm{H}_{8} \mathrm{NCl}\right)$. The ions $\mathrm{m} / z$ 110, 125, 263 and 110, 159, 297 were monitored for quantification of ticlopidine and internal standard, respectively.

\subsection{Quantification}

A constant amount of the internal standard was added to calibration standards just before injection. The peak measurements used were based on the extracted ion current profiles for the specific characteristic ions of each calibration standard and internal standard.

\subsection{Determination in real samples}

The suitability of the method validated was evaluated in plasma samples collected from healthy volunteers following oral administration of a $500 \mathrm{mg} /$ day dose. Blood samples were collected after 1.0, 2.0, 3.0, 4.0, 5.0 and $6.0 \mathrm{~h}$ after the administration of ticlopidine dose.

\subsection{Validation results}

The limits of detection (LODs) and quantification (LOQs) were estimated in accordance to the base line noise, considering a signal-to-noise ratio of 3:1 and 10:1, respectively. The values obtained for this method, calculated by spiking sample

Table 1

Assay linearity for ticlopidine

\begin{tabular}{llll}
\hline & $r$-Value & Slope \pm S.D. & Intercept \pm S.D. \\
\hline Intra-day precision & 0.9994 & $5.87 \times 10^{-3} \pm 0.30 \times 10^{-3}$ & $0.083 \pm 0.105$ \\
$(n=5)$ & R.S.D. $=0.09 \%$ & R.S.D. $=5.8 \%$ & $-0.057 \pm 0.142$ \\
Inter-day precision & 0.9990 & $6.39 \times 10^{-3} \pm 0.78 \times 10^{-3}$ & \\
$(n=5)$ & R.S.D. $=0.16 \%$ & R.S.D. $=9.6 \%$ & \\
\hline
\end{tabular}

R.S.D., relative standard deviation. 


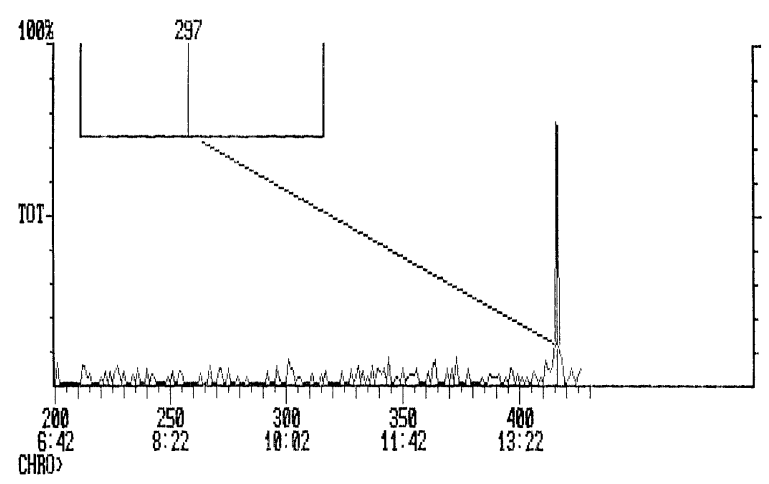

Fig. 5. Total ion chromatogram of extract of bank plasma.

extracts of bank plasma, were $0.005 \mu \mathrm{g} / \mathrm{ml}$ for LOD and $0.01 \mu \mathrm{g} / \mathrm{ml}$ for LOQ.

The calibration graphs for the standard of ticlopidine was obtained by plotting the ratio of the peak areas of the ticlopidine standard and the internal standard, against their concentration ratio between 0.01 and $2.5 \mu \mathrm{g} / \mathrm{ml}$, i.e. at $0.01,0.05,0.2$, $0.5,1.0,2.0$ and $2.5 \mu \mathrm{g} / \mathrm{ml}$, respectively.

Peak area of ticlopidine over the I.S. varied linearly with concentration over the range used. Intra-assay precision was determined for calibration curves prepared the same day in replicate, and inter-assay precision was determined for calibration curves prepared on different days. Results are given in Table 1. For each point of calibration standards, the concentrations were back-calculated from the equation of the linear regression curves and the R.S.D.s determined. The linearity of the method was confirmed by comparing the slopes and the intercepts of linear calibration curves with zero, and the correlation coefficients with 1 .

No significantly interfering peaks from the matrix were observed at the retention times of both ticlopidine and internal standard, as we can observed in the total ion chromatogram of the blank assay (Fig. 5).

The accuracy and within-day and the betweenday precision of the present method were determinate by performing extraction batches of samples of blank plasma, at two fortification levels, 0.01 and $2.5 \mu \mathrm{g} / \mathrm{l}$ and one blank (to check for interference), in duplicate for 3 days.

\section{Discussion}

The solid-phase extraction was chosen because of its efficiency and the relative speed compared with conventional liquid-liquid extraction. It was performed using Extrelut-1 columns, according Arnoux et al. method [12]. Moreover, these columns compared with reversed-phase liquidsolid extraction columns no conditioning or washing is necessary.

Although Róna et al. [8] reported lower recovery than the obtained by Arnoux et al. [12], our results are similar to Arnoux values. The formers have used a Bond Elut $\mathrm{C}_{18}$ solid-phase extraction for the isolation of the compounds from plasma.

Comparing the three methods (HPLC-UV, GCNPD and GC-MS) reported for the determination of ticlopidine from human serum, Arnoux et al. [12] found that HPLC reproducibility was acceptable down to $0.05 \mu \mathrm{g} / \mathrm{ml}$ and the limit of quantification was again $0.05 \mu \mathrm{g} / \mathrm{ml}$. On the contrary, Furlan et al. [10] state that for the HPLC method developed in their laboratory, the limit of reproducible and accurately quantifiable sensitivity is $0.02 \mu \mathrm{g} / \mathrm{ml}$, whereas the lowest detectable concentration is $0.01 \mu \mathrm{g} / \mathrm{ml}$, and hence comparable with determination levels reported by GC-NPD [11,12].

The limit of quantification of the HPLC method optimised by Bo et al. [6], proved to be as low as $0.005 \mu \mathrm{g} / \mathrm{ml}$ with values of precision of $8.51 \%$. Although these values are comparable with the values obtained with GC-MS, it lacks specificity, it do not allow the confirmation of identity of the compounds. Using HPLC, problems of specificity were observed by Arnoux et al. [12], since endogenous compounds were found to alter reproducibility.

The reported GC-MS method [12] uses a quadruple detector whereas in our laboratory we have used an ITD.

In the EC guidelines the monitoring of three ions, the molecular ion and two structurally significant fragment ions, is advised [14]. The presence of the analytes was determined by the presence of the three selected ions, the molecular and two fragment ions at the correct retention time and with the correct abundance ratio [14]. The 
Table 2

Inter and intra-assay validation results of ticlopidine from human serum

\begin{tabular}{llllll}
\hline Fortification level $(\mu \mathrm{g} / \mathrm{ml})$ & Number assay $(n)$ & Recovery variation $(\%)$ & Recovery mean $(\%)$ & $\% \mathrm{CV}$ intra-day & $\% \mathrm{CV}$ inter-day \\
\hline 0.01 & 6 & $82.9-87.5$ & 84.4 & 6.9 & 8.6 \\
0.2 & 6 & $86.1-91.0$ & 87.3 & 5.1 & 7.3 \\
\hline
\end{tabular}

$\mathrm{CV}$, coefficient of variation.

retention times for ticlopidine and internal standard were 11.9 and 13.7 , respectively.

Ticlopidine yield molecular ion at $\mathrm{m} / \mathrm{z} 263$ and two fragment ions, at $\mathrm{m} / \mathrm{z} 110$ and 125 , that were monitored, and permit it easy identification. Therefore, the limit of quantification obtained by our experimental conditions was slightly higher compared with the mass spectrometric method proposed by Arnoux et al. [12] where only the molecular ion was monitored. At low concentrations the monitoring of three ions could be insufficient due the influence of co-extracted matrix components and in case of doubt a full scan identification was also performed.

Low background interferences in human serum easily permitted the limit of detection achieved $0.005 \mu \mathrm{g} / \mathrm{ml}$.

During the development of the method, the internal standard, ticlopidine dichloro derivative was essential for accurate quantification of ticlopidine in biological samples.

Experiments with spiked human serum samples showed that mean recoveries ranged from 84.4 to $87.3 \%$ at fortification levels, 0.01 and $2.0 \mu \mathrm{g} / \mathrm{ml}$.

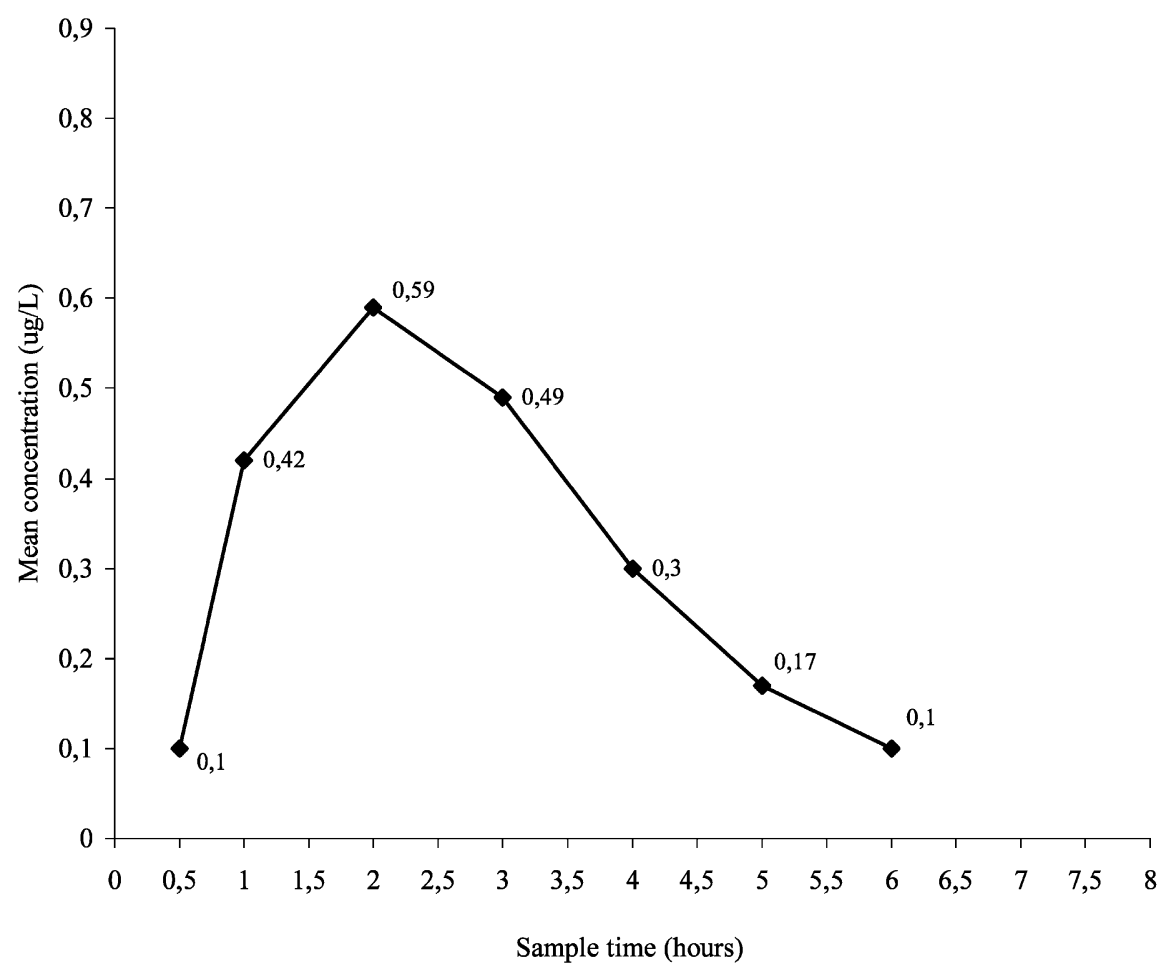

Fig. 6. Mean plasma concentration of ticlopidine after single 500-mg oral dose. 
The absolute recovery values were high and the concentration dependence of recovery was negligible, as we can observe in Table 2. Within and between-day precision $\mathrm{CV} \%$ values, obtained by analysing duplicate batches during 3 days, were lower than $10 \%$, ranging between 5.1 and $8.6 \%$ (Table 2). The results of linearity, accuracy and precision obtained assess the performance of the proposed method.

The method was applied to healthy volunteers in order to evaluate its application to routine assessment of ticlopidine plasma concentrations in pharmacokinetic studies following therapeutic doses in human subjects.

Mean plasma concentrations of ticlopidine of 10 healthy volunteers, measured by GC with ion trap detection fell from $0.59 \mathrm{mg} / \mathrm{l}$ at $2 \mathrm{~h}$ to $0.10 \mathrm{mg} / \mathrm{l}$ at 6 h post-dose, following a $500 \mathrm{mg}$ /day dose (Fig. 6). The time taken to achieve the maximal plasma concentration was approximately $2 \mathrm{~h}$ and it is in agreement with others studies $[13,15,16]$.

All the validated parameters, accuracy, sensitivity and precision, were within the necessary limits. Therefore, the developed analytical method was found to be suitable for the determination of ticlopidine plasmatic concentrations in healthy volunteers.

\section{References}

[1] S. Ashida, Y. Abiko, Thromb. Haemost. 9 (1978) $487-$ 490.

[2] J.P. Desager, Clin. Pharmacokinet. 26 (1994) 347-355.

[3] A. Tuong, A. Bouyssou, J. Paret, T.G. Cuong, Eur. J. Drug Metab. Pharmac. 6 (1981) 91-98.

[4] J.R. O'Brien, M.D. Etherington, R.D. Shuttleworth, Thromb. Res. 12 (1978) 1157.

[5] E. Saltiel, A. Ward, Drugs 34 (1987) 222-262.

[6] L.D. Bo, F. Verga, A. Marzo, L. Ambrosoli, A. Poli, J. Chromat. B 665 (1995) 404-409.

[7] S. Itoh, S. Suzuki, S. Ando, Y. Funatsu, M. Yamazaki, K. Tanabe, M. Sawanoi, Chem. Pharm. Bull. 35 (1987) 13041307.

[8] K. Rona, K. Ary, B. Gachalyi, I. Klebovich, J. Chromat. B 693 (1997) 393-398.

[9] K. Rona, K. Ary, B. Gachalyi, Acta Pharm. Hung. 67 (1997) 25-29.

[10] G. Furlan, N. Malusa, A. Strohmayer, F.B. klugmann, G. Decorti, L. Candussio, S. Klugmann, Farmaco 51 (1996) $747-751$.

[11] J. Shah, P. Teitelbaum, B. Molony, T. Gabuzda, I. Massey, Brit. J. Clin. Pharmacol. 32 (1991) 761-764.

[12] P. Arnoux, Y. Sales, M. Mandray, P. Lechat, Y. Berger, J.P. Cano, J. Pharm. Sci. 80 (1991) 1092-1096.

[13] J. Shah, A Fratis, D. Ellis, S. Murakami, P. Teitelbaum, J. Clin. Pharmacol. 30 (1990) 733-736.

[14] W.G. De Ruig, R.W. Stephany, G. Dijkstra, JAOAC 72 (1989) 487-492.

[15] J.B. Knudsen, W. Bastain, C.M. Sefton, Xenobiotica 22 (1992) 579-589.

[16] J. Shah, P. Teitelbaum, B. Molony, Brit. J. Clin. Pharmacol. 32 (1991) 761-764. 